\title{
The Effect of Hygroscopic Growth on Continental Aerosols
}

\author{
Bello Idrith Tijjani ${ }^{1}$, Aliyu Aliyu ${ }^{2}$, Fatima Shuaibu ${ }^{3}$ \\ ${ }^{1}$ Department of Physics, Bayero University, Kano, Nigeria \\ ${ }^{2}$ Department of Science Laboratory Technology, School of Technology, Kano State Polytechnic, Kano, Nigeria \\ ${ }^{3}$ Girl's Science and Technical College, Kano, Nigeria \\ Email: idrith@yahoo.com, idrithtijjani@gmail.com
}

Received July 11, 2013; revised August 30, 2013; accepted September 12, 2013

Copyright (C) 2013 Bello Idrith Tijjani et al. This is an open access article distributed under the Creative Commons Attribution License, which permits unrestricted use, distribution, and reproduction in any medium, provided the original work is properly cited.

\begin{abstract}
In this paper, the authors investigated some microphysical and optical properties of continental clean aerosols from OPAC to determine the effect of hygroscopic growth at the spectral range of $0.25 \mu \mathrm{m}$ to $2.5 \mu \mathrm{m}$ and eight relative humidities (RHs) $(0 \%, 50 \%, 70 \%, 80 \%, 90 \%, 95 \%, 98 \%$ and $99 \%)$. The microphysical properties extracted were radii, volume mix ratio, number mix ratio and mass mix ratio as a function of RH while the optical properties are scattering and absorption coefficients and asymmetric parameters. Using the microphysical properties, growth factors of the mixtures were determined while using optical properties the enhancement parameters were determined and then parameterized using some models. We observed that the data fitted the models very well. The angstrom coefficients show that the mixture has bimodal type of distribution with the dominance of fine mode particles.
\end{abstract}

Keywords: Microphysical Properties; Optical Properties; Hygroscopic Growth; Parametrization; Enhancement Parameters; Angstrom Coefficients

\section{Introduction}

Aerosol in the atmosphere is comprised of numerous and diverse components originating from both natural and anthropogenic activities.

An important factor affecting the role aerosols play in climate change is their hygroscopicity and is currently modeled in global climate models (GCMs), mostly to better predict the scattering properties and size distribution under varying humidity conditions [1]. The swelling of aerosols due to water vapor uptake will enhance their ability to scatter radiation. Numerous studies have investigated the relationship between aerosol scattering and relative humidity RH in terms of the hygroscopic growth factor $g f(\mathrm{RH})$ using humidified nephelometers. These have been used for airborne or ground-based determination of the growth factor considering a "dry" RH over the range from $20 \%-40 \%$ and a "wet" RH up to $90 \%$ [2-5].

The characterization of particle hygroscopicity has primary importance for climate monitoring and prediction. Model studies have demonstrated that relative humidity $(\mathrm{RH})$ has a critical influence on aerosol climate forcing. Hygroscopic properties of aerosols influence particle size distribution and refractive index and hence their radiative effects. Aerosol particles tend to grow at large relative humidity values as a result of their hygro- scopicity.

Some aerosol particles, such as ammonium sulphate $\left(\mathrm{NH}_{4}\right)_{2} \mathrm{SO}_{4}$, sea salt and ammonium nitrate $\mathrm{NH}_{4} \mathrm{NO}_{3}$ are hygroscopic. Changes in relative humidity modify their size distribution and refractive index and hence the optical properties of the aerosol, including the scattering coefficient [6-9]. Jeong et al. [10] demonstrated an exponential dependence of the aerosol optical thickness on relative humidity. A strong correlation of spectral aerosol optical thickness with precipitable water, especially for continental air masses, was shown by Rapti [11].

Water-soluble organic carbon (WSOC) species are emitted as primary particles, especially during biomass combustion, and produced as a result of reactions in the gas and aqueous phases [12-18]. Moreover, WSOC has been suggested as a marker for secondary organic aerosol (SOA) in the absence of biomass burning (e.g., Docherty et al. [19]).

In a study of aged continental aerosols, Swietlicki et al. [7] observed 2 modes, a less hygroscopic mode with a $g f(\mathrm{RH})$ of 1.12 and a more hygroscopic mode with a $g f(\mathrm{RH})$ between 1.44 and 1.65 . They postulated that the hygroscopic growth could be attributed entirely to the inorganic content of the aerosol: sulfate, nitrate and ammonium ions. Particle hygroscopicity may vary as a fun- 
ction of time, place and particle size [20-22]. The size and the solubility of a particle determine the response of an ambient particle to changes in RH. The water vapor pressure above a water droplet containing dissolved material is lowered by the Raoult effect. The equilibrium size of a droplet was first described by Kohler [23], who considered the Kelvin (curvature) and Raoult (solute) effect. Using optical properties, several previous studies (e.g. Sheridan et al. [24]) have measured and modeled enhancement factors for continental aerosols.

The aim of this study is to determine the aerosols' hygroscopic growth and enhancement factors for continenttal clean aerosols from the data extracted from OPAC. One variable and two variables parameterizations models will be performed to determine the relationship of the particles' hygroscopic growth and enhancement parameters with the RH. Angstrom coefficients are used to determine the particles' type and the type mode size distributions.

\section{Methodology}

The models extracted from OPAC are given in Table 1.

The main parameter used to characterize the hygroscopicity of the aerosol particles is the aerosol hygroscopic growth factor $g f(\mathrm{RH})$, which indicates the relative increase in mobility diameter of particles due to water absorption at a certain $\mathrm{RH}$ and is defined as the ratio of the particle diameter at any $\mathrm{RH}$ to the particle diameter at $\mathrm{RH}=0$ and RH is taken for seven values $50 \%, 70 \%$, $80 \%, 90 \%, 95 \%, 98 \%$ and $99 \%[22,26]$ :

$$
g f(\mathrm{RH})=\frac{D(\mathrm{RH})}{D(\mathrm{RH}=0)}
$$

The $g f(\mathrm{RH})$ can be subdivided into different classes with respect hygroscopicity. One classification is based on diameter growth factor by Liu et al. [27] and Swietlicki et al., [22] as barely hygroscopic $(g f(\mathrm{RH})=1.0-$ $1.11)$, less Hygroscopic $(g f(\mathrm{RH})=1.11-1.33)$, more Hygroscopic $(g f(\mathrm{RH})=1.33-1.85)$ and most hygroscopic growth $(g f(\mathrm{RH})>1.85)$.

Atmospheric particles of a defined dry size typically exhibit different growth factors. This is due to either external mixing of particles in an air sample or variable relative fractions of different compounds in individual

Table 1. Compositions of aerosol type [25].

\begin{tabular}{ccc}
\hline Aerosol model types & Components & Concentration $\mathrm{N}_{\mathrm{i}}\left(\mathrm{cm}^{-3}\right)$ \\
\hline \multirow{3}{*}{ Continental clean } & WASO & 2600.0 \\
& INSO & 0.15 \\
& Total & 26000.15 \\
\hline
\end{tabular}

Note: $\mathrm{N}_{\mathrm{i}}$ is the mass concentration of the component, water soluble components (WASO, consists of scattering aerosols, that are hygroscopic in nature, such as sulfates and nitrates present in anthropogenic pollution) and water insoluble (INSO). particles (the latter here in after referred to as quasi-internally mixed). A mono-modal growth distribution without spread can only be expected in very clean and homogeneous air parcels. For further details on mixing states see e.g. Buzorius et al. [28].

Most atmospheric aerosols are externally mixed with respect to hygroscopicity, and consist of more and less hygroscopic sub-fractions [22]. The ratio between these fractions as well as their content of soluble material determine the hygroscopic growth of the overall aerosol.

Prediction of hygroscopic growth factors with Kohler theory requires detailed knowledge of particle composition as well as a thermodynamic model, which describes the concentration dependence of the water activity for such a mixture. The hygroscopic growth factor of a mixture, $g f_{\text {mix }}(\mathrm{RH})$, can be estimated from the growth factors of the individual components of the aerosol and their respective volume fractions, $V_{k}$, using the ZdanovskiiStokes-Robinson relation and other researchers [29-32]:

$$
g f_{\text {mix }}(\mathrm{RH})=\left(\sum_{k} V_{k} g f_{k}^{3}\right)^{1 / 3}
$$

where the summation is performed over all compounds present in the particles. Solute-solute interactions are neglected in this model and volume additivity is also assumed. The model assumes spherical particles, ideal mixing (i.e. no volume change upon mixing) and independent water uptake of the organic and inorganic components.

It can also be computed using the corresponding number fractions $n_{k}$ as [33,34];

$$
g f_{\text {mix }}(\mathrm{RH})=\left(\sum_{k} n_{k} g f_{k}^{3}\right)^{1 / 3}
$$

where $n_{k}$ is the number fraction of particles having the growth factor $g f_{k}$.

We now proposed the $g f_{\text {mix }}(\mathrm{RH})$ to be a function of mass mix ratio as

$$
g f_{\text {mix }}(\mathrm{RH})=\left(\sum_{k} m_{k} g f_{k}^{3}\right)^{1 / 3}
$$

where $m_{k}$ represents the mass mix ratio of particles having the growth factor $g f_{k}$.

The RH dependence of $g f_{\text {mix }}(\mathrm{RH})$ were parameterized in a good approximation by a one-parameter equation, proposed e.g. by Petters and Kreidenweis [35]:

$$
g f_{\text {mix }}\left(a_{w}\right)=\left(1+\kappa \frac{a_{w}}{1-a_{w}}\right)^{\frac{1}{3}}
$$

Here, $a_{w}$ is the water activity, which can be replaced by the relative humidity RH, if the Kelvin effect is negligible, as for particles with sizes more relevant for light scattering and absorption. At equilibrium, it can be shown that, over a flat surface, the water activity equals the ambient relative humidity in the sub-saturated humid 
environment [36,37]. The coefficient $\kappa$ is a simple measure of the particle's hygroscopicity and captures all solute properties (Raoult effect).

Humidograms of the ambient aerosols obtained in various atmospheric conditions showed that $g f_{m i x}(\mathrm{RH})$ could as well be fitted well with a $\gamma$-law [38-42] as

$$
g f_{\text {mix }}(\mathrm{RH})=\left(1-\frac{\mathrm{RH}}{100}\right)^{\gamma}
$$

Particle hygroscopicity is a measure that scales the volume of water associated with a unit volume of dry particle [35] and depends on the molar volume and the activity coefficients of the dissolved compounds [43].

The bulk hygroscopicity factor $B$ under subsaturation $\mathrm{RH}$ conditions was determined using the relation:

$$
B=\left(1-g f_{m i x}^{3}\right) \ln a_{w}
$$

where $a_{w}$ is the water activity, which can be replaced by the $\mathrm{RH}$ as explained earlier.

The impact of hygroscopic growth on the aerosol optical properties is usually described by the enhancement factor $f_{\chi}(\mathrm{RH}, \lambda)$ :

$$
f_{\chi}(\mathrm{RH}, \lambda)=\frac{\chi(\mathrm{RH}, \lambda)}{\chi(\mathrm{RH}=0, \lambda)}
$$

where $\chi(\mathrm{RH}, \lambda)$ can be denoting the aerosol scattering and absorption coefficients, and asymmetry parameters. RH corresponds to any condition, and can cover the entire RH spectrum. In this paper we will only use scattering, absorption and asymmetric parameter. The reason for using asymmetric parameter is to determine the effect of hygroscopic growth on forward scattering. This method was initially introduced by Covert et al. [2].

In general the relationship between $f_{\chi}(\mathrm{RH}, \lambda)$ and $\mathrm{RH}$ is nonlinear (e.g. Jeong et al. [10]). In this paper we determine the empirical relations between the enhancement parameter and $\mathrm{RH}[44]$ as:

$$
f_{\chi}(\mathrm{RH}, \lambda)=\frac{\chi(\mathrm{RH}, \lambda)}{\chi(\mathrm{RH}=0, \lambda)}=\left(\frac{100-\mathrm{RH}_{r e f}}{100-\mathrm{RH}_{h i g h}}\right)^{\gamma}
$$

where in our study $R H_{r e f}$ is $0 \%$. The $\gamma$ known as the humidification factor represents the dependence of aerosol optical properties on $\mathrm{RH}$, which results from changes in the particle size and refractive index upon humidification. The parameter in our case was obtained by combining the eight $\chi(\mathrm{RH}, \lambda)$ parameters at $0 \%, 50 \%, 70 \%, 80 \%$, $90 \%, 95 \%, 98 \%$ and $99 \%$ RH. The use of $\gamma$ has the advantage of describing the hygroscopic behavior of aerosols in a nonlinear manner over a broad range of $\mathrm{RH}$ values; it also implies that particles are deliquesced [45], a reasonable assumption for this data set due to the high ambient relative humidity during the field study. The $\gamma$ parameter is dimensionless, and it increases with in- creasing particle water uptake. From previous studies, typical values of $\gamma$ for ambient aerosol ranged between 0.1 and 1.5 [45-47].

Two parameters empirical relation is also used $[10,48]$ as:

$$
f_{\chi}(\mathrm{RH}, \lambda)=a\left(1-\frac{\mathrm{RH}(\%)}{100}\right)^{b}
$$

The model assumes equilibrium (metastable) growth of the aerosol scattering with RH such that the humidigraph profile does not display a deliquescent growth profile. For aerosol in a humid environment, this behavior will hold true. Most aerosols are a mixture of metastable and deliquescent particles and will exhibit some deliquescent behavior. To verify the non-linearity of the relation between $f_{\chi}(\mathrm{RH}, \lambda)$ and $\mathrm{RH}$, the Equations (9) and (10) were modeled at $\lambda=0.25,1.25$ and $2.50 \mu \mathrm{m}$.

The Angstrom exponent being an indicator of the aerosol spectral behaviour of aerosols [49], the spectral behavior of the aerosol optical parameter ( $X$, say), with the wavelength of light $(\lambda)$ is expressed as inverse power law [50]:

$$
X(\lambda)=\beta \lambda^{-\alpha}
$$

where $X(\lambda)$ can represent scattering and absorption coefficients. The variable $X(\lambda)$ can be characterized by the Angstron parameter, which is a coefficient of the following regression,

$$
\ln X(\lambda)=-\alpha \ln (\lambda)+\ln \beta
$$

however the Angstrom exponent itself varies with wavelength, and a more precise empirical relationship between aerosol extinction and wavelength is obtained with a 2nd-order polynomial [51-61], as:

$$
\ln X(\lambda)=\alpha_{2}(\ln \lambda)^{2}+\alpha_{1} \ln \lambda+\ln \beta
$$

and then we proposed the cubic

$$
\ln X(\lambda)=\ln \beta+\alpha_{1} \ln \lambda+\alpha_{2}(\ln \lambda)^{2}+\alpha_{3}(\ln \lambda)^{3}
$$

where $X(\lambda)$ can be any of the optical parameter, $\beta, \alpha$, $\alpha_{1}, \alpha_{2}, \alpha_{3}$ are constants that are determined using regression analysis with SPSS16.0.

We also determine the effect of hygroscopic growth on the effective refractive indices of the two mixed aerosols using the following formula [62]:

$$
\frac{\varepsilon_{e f f}-\varepsilon_{0}}{\varepsilon_{e f f}+2 \varepsilon_{0}}=\sum_{i=1}^{2} f_{i} \frac{\varepsilon_{i}-\varepsilon_{0}}{\varepsilon_{i}+2 \varepsilon_{0}}
$$

where $f_{i}$ and $\varepsilon_{i}$ are the volume fraction and dielectric constant of the $i^{\text {th }}$ component and $\varepsilon_{0}$ is the dielectric constant of the host material. For the case of Lorentz-Lorentz $[63,64]$, the host material is taken to be vacuum, $\varepsilon_{0}=1$. 


\section{Results and Observations}

Figure 1 is the plot from the data of Table 2, and it shows non-linear relation $g f_{\text {mix }}$ with $\mathrm{RH}$, (a steep curve) with deliquescence observed at relative humidities as from $90 \%$ to $99 \%$ RH.

The results of the parameterizations by one and two parameters of Equations (5) and (6) are:

$$
\begin{aligned}
& \mathrm{C}=1.433571, \mathrm{k}=0.012412, \mathrm{R}^{2}= 0.8731 \\
& \text { from Equation (5) } \\
& \gamma=-0.069589, \mathrm{R}^{2}=0.9962 \text { from Equation (6) }
\end{aligned}
$$

The fitted curve can be represented by one and two empirical parameters fit of the form of Equations (5) and (6), though Equation (6) has higher coefficient of determination.

Figure 2 is a plot from the data of Table 2, and shows non-linear relation B with RH, (a steep curve) with deliquescence observed at relative humidities as from $90 \%$ to 99\% RH.

Figure $\mathbf{3}$ is a plot from the data of Table 3, and it shows an increase in particle diameter with increasing $\mathrm{RH}$ and shows a steep curve with deliquescence observed at relative humidities as from $90 \%$ to $99 \% \mathrm{RH}$.

The results of the parameterizations by a one and two parameters of Equations (5) and (6) are:

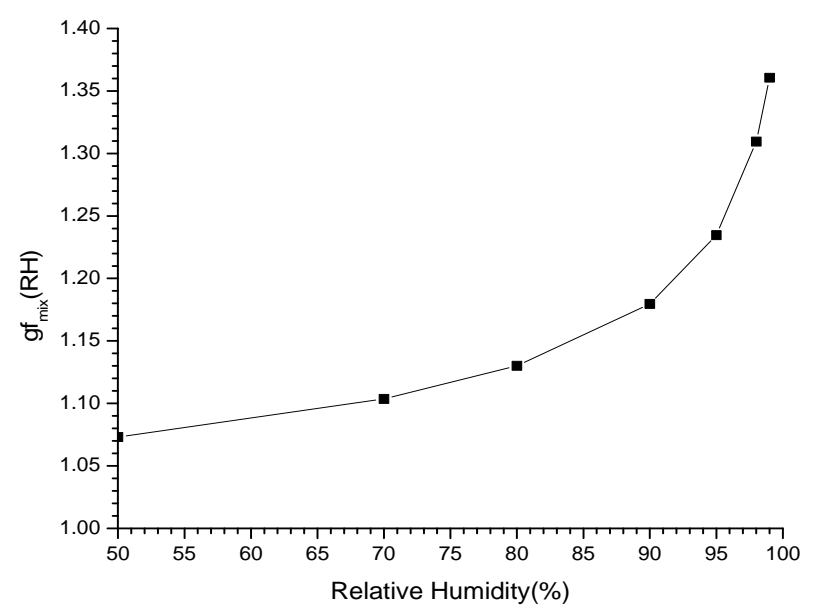

Figure 1. A graph of growth factor of the mixture using number mix ratio (Equation (3)) against $\mathrm{RH}$.

Table 2. The growth factor of the aerosols using number mix ratio (Equation (3)) and bulk hygroscopicity factor (Equation (7)).

\begin{tabular}{cccccccc}
\hline $\mathrm{RH}(\%)$ & 50 & 70 & 80 & 90 & 95 & 98 & 99 \\
\hline$g f_{\text {mix }}(\mathrm{RH})$ & 1.0731 & 1.1036 & 1.1301 & 1.1796 & 1.2346 & 1.3094 & 1.3606 \\
$\begin{array}{c}\text { Bulk } \\
\text { Hygroscopicity } \\
\text { factor (B) }\end{array}$ & 0.1634 & 0.1228 & 0.0989 & 0.0676 & 0.0452 & 0.0252 & 0.0153 \\
\hline
\end{tabular}

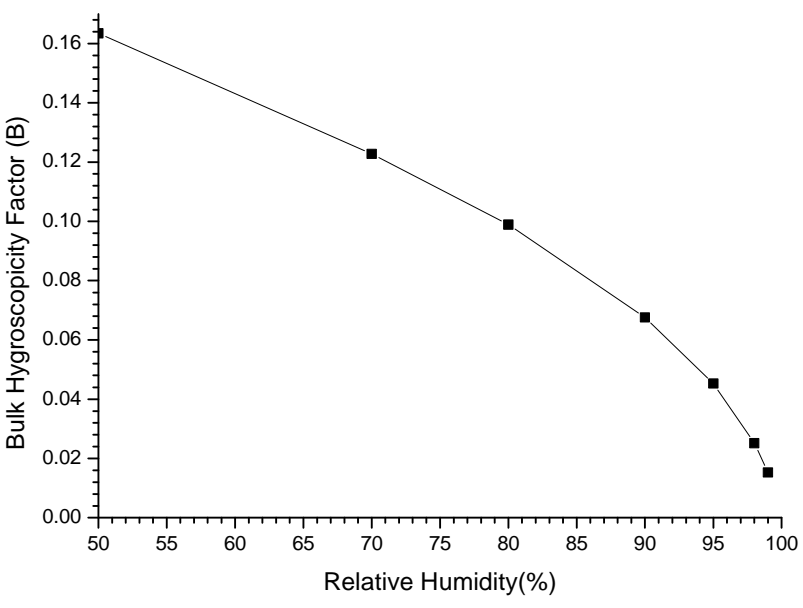

Figure 2. Bulk hygroscopcity factor of the mixture using number mix ratio (Equation (7)).

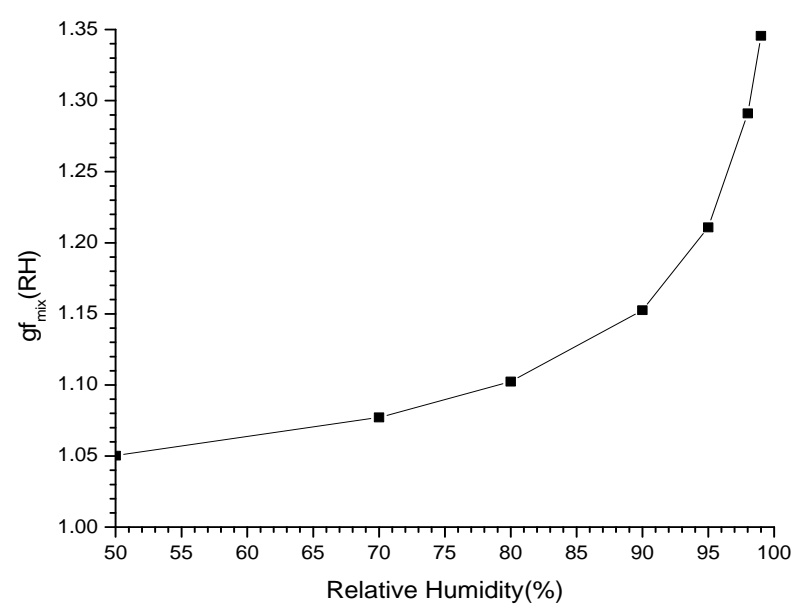

Figure 3. A graph of growth factor of the mixture using volume mix ratio (Equation (2)).

Table 3. The growth factor of the aerosols using volume mix ratio (Equation (2)) and bulk hygroscopicity factor (Equation (7)).

\begin{tabular}{cccccccc}
\hline $\mathrm{RH}(\%)$ & 50 & 70 & 80 & 90 & 95 & 98 & 99 \\
$g f_{\text {mix }}(\mathrm{RH})$ & 1.0503 & 1.0772 & 1.1024 & 1.1526 & 1.2108 & 1.2910 & 1.3456 \\
Bulk & & & & & & &
\end{tabular}

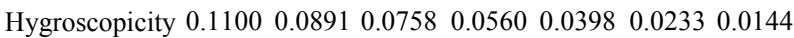
factor (B)

$$
\begin{array}{r}
\mathrm{C}=1.334733, \mathrm{k}=0.012542, \mathrm{R}^{2}=0.8860 \\
\text { from Equation (5) } \\
\gamma=-0.064125, \mathrm{R}^{2}=0.9995 \text { from Equation (6) }
\end{array}
$$

The fitted curve can be represented by one and two empirical parameters fit of the form of Equations (5) and (6), though Equation (6) has higher coefficient of determination.

Figure $\mathbf{4}$ is a plot from the data of Table 3 , is almost the 
same as Figure 2.

Figure 5 is a plot from the data of Table 4, it shows an increase in particle diameter with increasing $\mathrm{RH}$ and shows a steep curve with deliquescence observed at relative humidities as from $90 \%$ to $99 \% \mathrm{RH}$.

The results of the parameterizations by a one and two parameters of Equations (5) and (6) are:

$$
\mathrm{C}=1.294418, \mathrm{k}=0.012166, \mathrm{R}^{2}=0.8983
$$

from Equation (5)

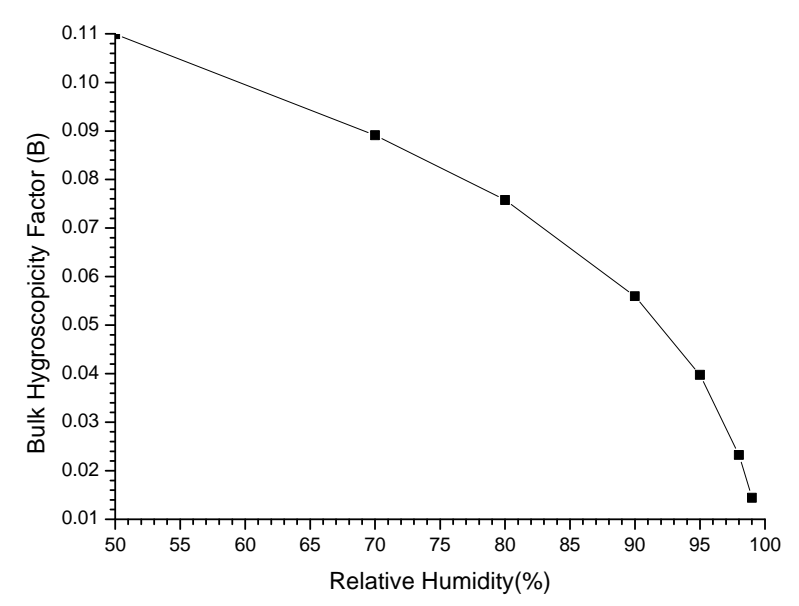

Figure 4. Bulk Hygroscopcity factor of the mixture using volume mix ratio (Equation (7)).

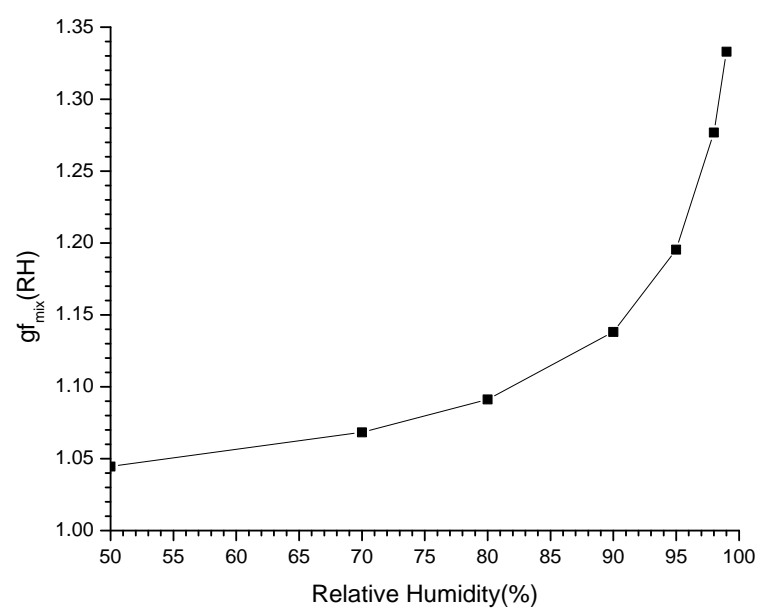

Figure 5. A graph of growth factor of the mixture using mass mix ratio (Equation (4)).

Table 4. The growth factor of the aerosols using mass mix ratio (Equation (4)) and bulk hygroscopicity factor (Equation (7)).

\begin{tabular}{cccccccc}
\hline $\mathrm{RH}(\%)$ & 50 & 70 & 80 & 90 & 95 & 98 & 99 \\
\hline$g f_{\text {mix }}(\mathrm{RH})$ & 1.0446 & 1.0684 & 1.0912 & 1.1382 & 1.1953 & 1.2768 & 1.3331 \\
$\quad$ Bulk & & & & & & & \\
$\begin{array}{c}\text { Hygroscopicity } \\
\text { factor (B) }\end{array}$ & 0.0970 & 0.0783 & 0.0668 & 0.0500 & 0.0363 & 0.0218 & 0.0138 \\
\hline
\end{tabular}

$$
\gamma=-0.060798, \mathrm{R}^{2}=0.9981 \text { from Equation (6) }
$$

The fitted curve can be represented by one and two empirical parameters fit of the form of Equations (5) and (6), though Equation (6) has higher coefficient of determination.

Figure 6 is a plot from the data of Table 4, is the same as Figures $\mathbf{2}$ and 4.

Figure 7 shows that scattering increases substantially as a result of the increase in hygroscopic growth most especially at smaller wavelength. This shows the high concentration of smaller particles, and that hygroscopic growth has more effect on small particles. This increase is due to the growth of smaller particles to sizes at which they scatter more light being more pronounced than that for larger particles.

Table 5 shows that the linear part reflects the dominance of fine mode particles because $\alpha>1$ and has been verified by the sign of $\alpha_{2}$ as reported by [52,56,68-71] for the existence of negative curvatures for fine-mode aerosols and positive curvatures for coarse mode. As from

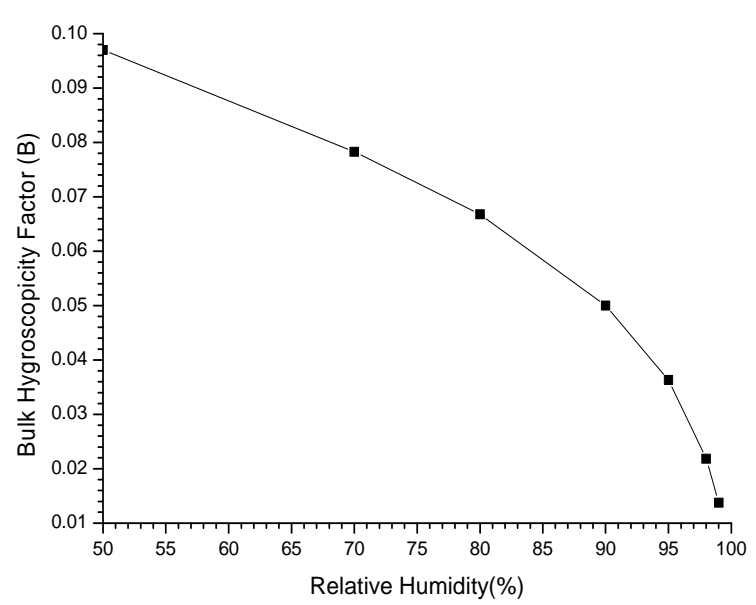

Figure 6. Figure 2; Bulk Hygroscopcity factor of the mixture using mass mix ratio (Equation (7)).

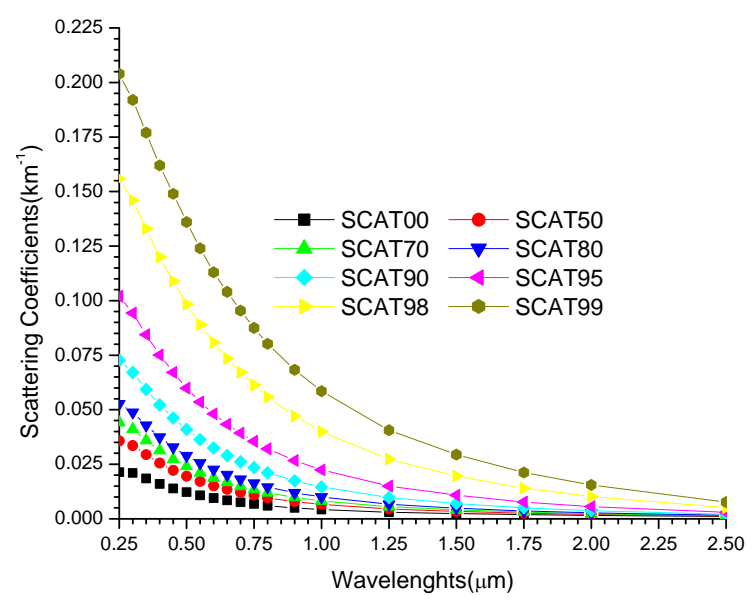

Figure 7. A plot of scattering coefficients against wavelength. 
Table 5. The results of the Angstrom coefficients of scattering coefficients using Equations (12)-(14) for continental clean model at the respective relative humidities using regression analysis with SPSS16.0.

\begin{tabular}{ccccccccccc}
\hline $\mathrm{RH}$ & \multicolumn{2}{c}{ Linear } & \multicolumn{3}{c}{ Quadratic } & \multicolumn{3}{c}{ Cubic } \\
\hline$(\%)$ & $\mathrm{R} 2$ & $\mathrm{~A}$ & $\mathrm{R}^{2}$ & $\alpha_{1}$ & $\alpha_{2}$ & $\mathrm{R}^{2}$ & $\alpha_{1}$ & $\alpha_{2}$ & $\alpha_{3}$ \\
\hline 0 & 0.9887 & 1.3858 & 0.9956 & -1.4647 & -0.1718 & 0.9991 & -1.6016 & -0.0156 & 0.2048 \\
50 & 0.9839 & 1.5029 & 0.9985 & -1.6276 & -0.2715 & 0.9997 & -1.7142 & -0.1727 & 0.1295 \\
70 & 0.9802 & 1.5327 & 0.9992 & -1.6781 & -0.3164 & 0.9998 & -1.7403 & -0.2454 & 0.0931 \\
80 & 0.9763 & 1.5483 & 0.9995 & -1.7108 & -0.3537 & 0.9998 & -1.7522 & -0.3065 & 0.0619 \\
90 & 0.9682 & 1.5522 & 0.9998 & -1.7429 & -0.4151 & 0.9998 & -1.7469 & -0.4106 & 0.0060 \\
95 & 0.9586 & 1.5227 & 0.9995 & -1.7371 & -0.4666 & 0.9997 & -1.7067 & -0.5013 & -0.0455 \\
98 & 0.9451 & 1.4423 & 0.9988 & -1.6764 & -0.5096 & 0.9995 & -1.6141 & -0.5807 & -0.0933 \\
99 & 0.9356 & 1.3710 & 0.9983 & -1.6127 & -0.5260 & 0.9993 & -1.5366 & -0.6129 & -0.1138 \\
\hline
\end{tabular}

$0 \%$ to $90 \%$ the hygroscopic growth has caused increase in $\alpha$ and increase in the curvature from the quadratic part. As from $95 \%, \alpha$ started decreasing and continued to decrease with the increase in RH despite the fact that $\alpha_{2}$ continued to increase. This shows that as the deliquescence point increase the values of $\alpha$ continued to decrease. It also shows that hygroscopic growth enhances mode size growth. The increase in $\alpha_{2}$ signifies the increase in the domination of fine particles. The cubic part shows that the mixture has bimodal type of distribution with the dominance of fine mode particles because the magnitude of $\alpha_{1}>1$.

Figure 8 shows that refractive indicies decrease with the increase in RH. It also shows that the non-sphericity increases with the increase in RH. This shows that increase in hygroscopic growth causes the particles to be more non-spherical with wavelengths.

Figure 9 shows that enhancement increases with the increase in hygroscopic growth and is also a function of wavelengths. Enhancement factor as a function of $\mathrm{RH}$ shows a nonlinear relation.

The results of the fitted curves of Equations (9) and (10) are presented as follows:

For one parameter (Equation (9))

At $\lambda=0.25 \mu, \gamma=0.512704, \mathrm{R}^{2}=0.9961$

At $\lambda=1.25 \mu, \gamma=0.552129, \mathrm{R}^{2}=0.9984$

At $\lambda=2.50 \mu, \gamma=0.367149, \mathrm{R}^{2}=0.9722$

For two parameters (Equation (10))

At $\lambda=0.25 \mu, \mathrm{a}=1.204648, \mathrm{~b}=-0.454391, \mathrm{R}^{2}=$ 0.9992

At $\lambda=1.25 \mu, \mathrm{a}=0.925221, \mathrm{~b}=-0.576471, \mathrm{R}^{2}=$ 0.9957

At $\lambda=2.50 \mu, \mathrm{a}=0.737846, \mathrm{~b}=-0.462366, \mathrm{R}^{2}=$ 0.9753

Because of the very good correlations, they verify the non-linearity relation between the enhancements parameters and $\mathrm{RH}$.

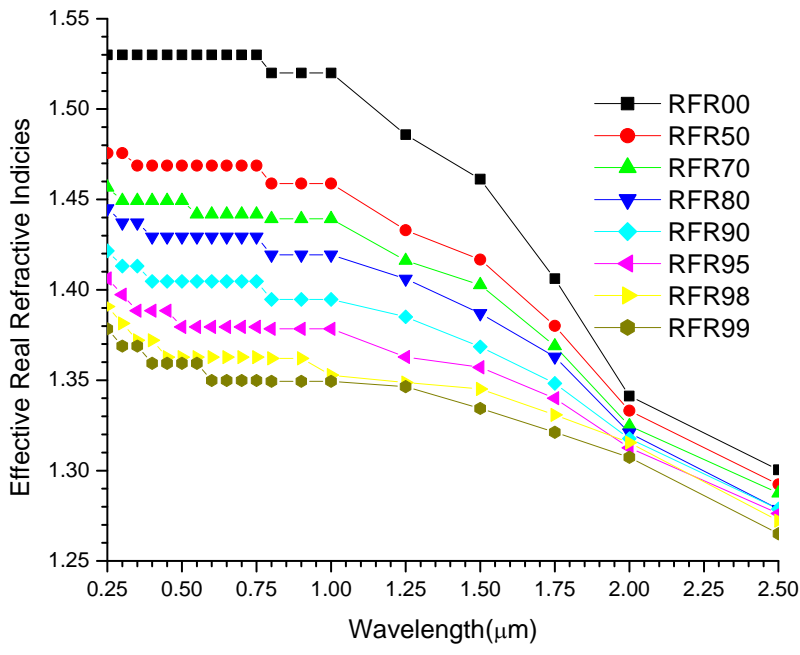

Figure 8. A plot of effective real refractive indices against wavelength.

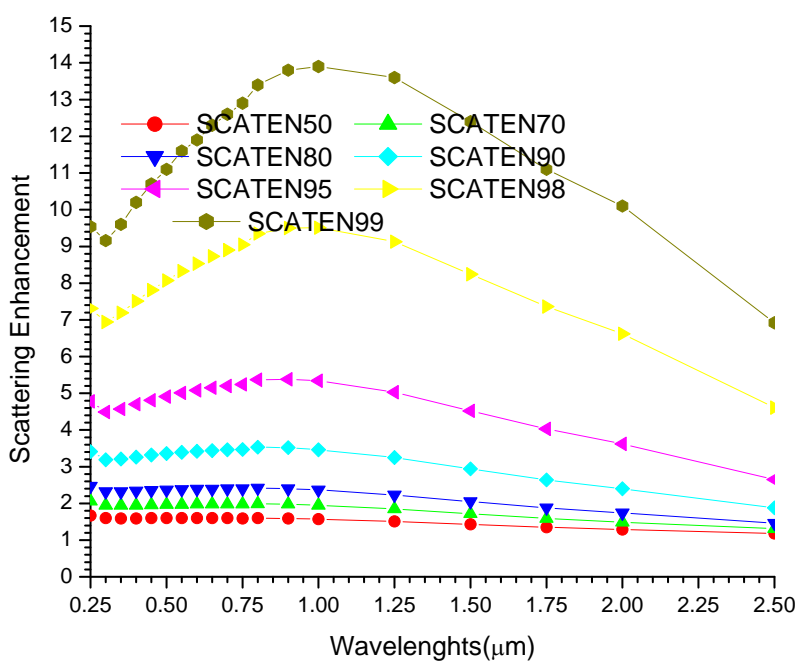

Figure 9. A plot of scattering enhancement parameters against wavelengths. 
Figure 10 shows that absorption is barely dependent of hygroscopic growth at smaller wavelengths but increases as the wavelengths increases. This shows that larger particles absorbs more than smaller as the hygroscopic growth increases. The plots can be approximated by power law.

From Table 6, the values of $\alpha$ shows the dominance of coarse particles because it is less than 1 . As the RH increases it also continued to decrease and the values of $\alpha_{2}$ continued to increase and positive throughout. This shows that increase in hygroscopic growth increases the particle size and shows the dominance of the coarse particles. This also verifies bi-modal type of particle size distribution.

From Figure 11, the behavior of the effective imaginary refractive indicies with wavelengths shows the dominance of non-spherical particles. It also shows decrease in refractive indicies as a result of the increase in hygroscopic growth. Comparing Figures 10 and $\mathbf{1 1}$ shows that particle has more dominance in absorption than the imaginary effective refractive indicies. This is because as a result of the decrease in the effective imaginery refractive indicies, we expect decrease in absorption instead of the increase as shown in Figure 10.

Figure 12 shows that the enhancement parameter increases with the increase in wavelengths and this implies increase with the increases of the particle size. This shows that it increases with the increase in particle size as observed in Figure 10.

Enhancement factor as a function of $\mathrm{RH}$ shows a nonlinear relation.

The results of the fitted curves of Equations (9) and (10) are presented as follows:

For one parameter (Equation (9))

$$
\begin{aligned}
& \text { At } \lambda=0.25 \mu, \gamma=0.033611, R^{2}=0.9799 \\
& \text { At } \lambda=1.25 \mu, \gamma=0.032435, R^{2}=0.9931
\end{aligned}
$$

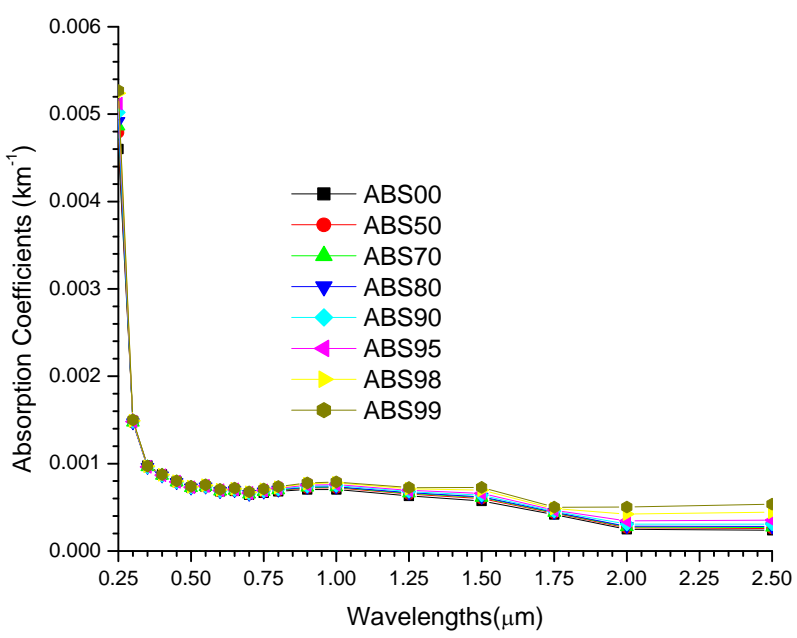

Figure 10. A plot of absorption coefficients against wavelength.

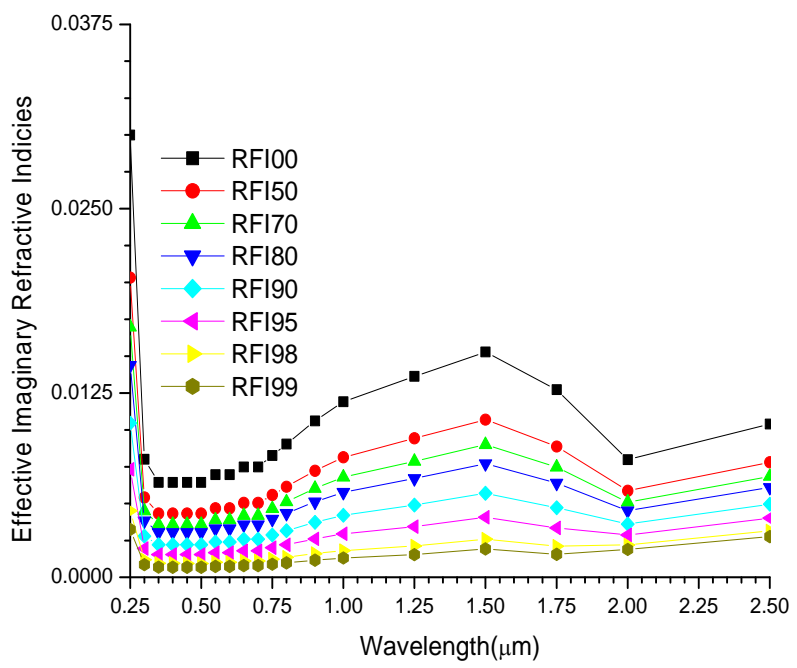

Figure 11. A plot of effective imaginary refractive indices against wavelength.

Table 6. The results of the Angstrom coefficients of absorption coefficients using Equations (12)-(14) for continental clean model at the respective relative humidities using regression analysis with SPSS16.0.

\begin{tabular}{ccccccccccc}
\hline RH & \multicolumn{2}{c}{ Linear } & \multicolumn{3}{c}{ Quadratic } & \multicolumn{3}{c}{ Cubic } \\
\hline$(\%)$ & $\mathrm{R}^{2}$ & $\alpha$ & $\mathrm{R}^{2}$ & $\alpha_{1}$ & $\alpha_{2}$ & $\mathrm{R}^{2}$ & $\alpha_{1}$ & $\alpha_{2}$ & $\alpha_{3}$ \\
0 & 0.7321 & 0.8145 & 0.7574 & -0.7114 & 0.2243 & 0.9472 & -0.0227 & -0.5615 & -1.0300 \\
50 & 0.6988 & 0.7801 & 0.7326 & -0.6633 & 0.2542 & 0.9397 & 0.0419 & -0.5504 & -1.0547 \\
70 & 0.6866 & 0.7655 & 0.7252 & -0.6419 & 0.2690 & 0.9368 & 0.0638 & -0.5362 & -1.0555 \\
80 & 0.6757 & 0.7518 & 0.7195 & -0.6214 & 0.2838 & 0.9343 & 0.0824 & -0.5193 & -1.0527 \\
90 & 0.6537 & 0.7228 & 0.7108 & -0.5773 & 0.3168 & 0.9293 & 0.1166 & -0.4749 & -1.0378 \\
95 & 0.6226 & 0.6824 & 0.7026 & -0.5158 & 0.3626 & 0.9219 & 0.1567 & -0.4047 & -1.0058 \\
98 & 0.5596 & 0.6126 & 0.6940 & -0.4082 & 0.4450 & 0.9083 & 0.2214 & -0.2733 & -0.9416 \\
99 & 0.4973 & 0.5532 & 0.6912 & -0.3180 & 0.5120 & 0.8954 & 0.2707 & -0.1597 & -0.8805 \\
\hline
\end{tabular}




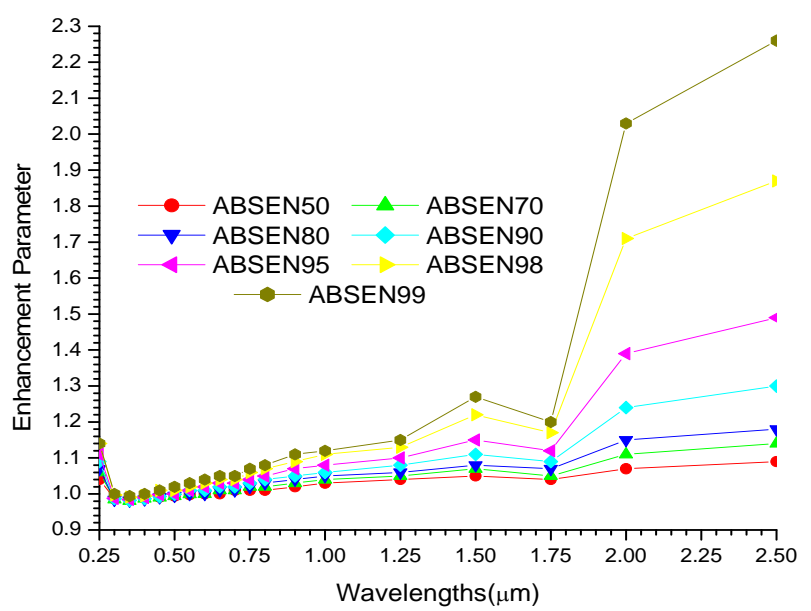

Figure 12. A plot of Absorption enhancement parameters against wavelengths.

At $\lambda=2.50 \mu, \gamma=0.153640, \mathrm{R}^{2}=0.9740$

For two parameters (Equation (10))

At $\lambda=0.25 \mu, \mathrm{a}=1.027460, \mathrm{~b}=-0.025126, \mathrm{R}^{2}=$ 0.9845

At $\lambda=1.25 \mu, \mathrm{a}=1.016064, \mathrm{~b}=-0.027444, \mathrm{R}^{2}=$ 0.9995

At $\lambda=2.50 \mu, \mathrm{a}=0.894238, \mathrm{~b}=-0.188649, \mathrm{R}^{2}=$ 0.9669

Because of the very good correlations, they verify the non-linearity relation between the enhancements parameters and $\mathrm{RH}$.

Figure 13 shows that hygroscopic growth causes smaller particles to scatter more in the forward and forward scattering decreases with the increase in particle size.

Figure 14 shows that hygroscopic growth causes enhancement in the forward direction to decrease with the increase in particle size.

The results of the fitted curves of Equations (9) and (10) are presented as follows:

For one parameter (Equation (9))

At $\lambda=0.25 \mu, \gamma=0.029089, \mathrm{R}^{2}=0.9291$

At $\lambda=1.25 \mu, \gamma=0.027159, \mathrm{R}^{2}=0.9826$

At $\lambda=2.55 \mu, \gamma=-0.060856, \mathrm{R}^{2}=0.9717$

For two parameters (Equation (10))

At $\lambda=0.25 \mu, \mathrm{a}=1.014671, \mathrm{~b}=-0.014565, \mathrm{R}^{2}=$ 0.9348

At $\lambda=1.25 \mu, \mathrm{a}=0.980473, \mathrm{~b}=-0.033335, \mathrm{R}^{2}=$ 0.9920

At $\lambda=2.50 \mu, \mathrm{a}=0.954266, \mathrm{~b}=0.046195, \mathrm{R}^{2}=0.9136$

Because of the very good correlations, they verify the non-linearity relation between the enhancements parameters and $\mathrm{RH}$.

\section{Conclusions}

From the $g f_{\text {mix }}(\mathrm{RH})$ determined, it can be observed that

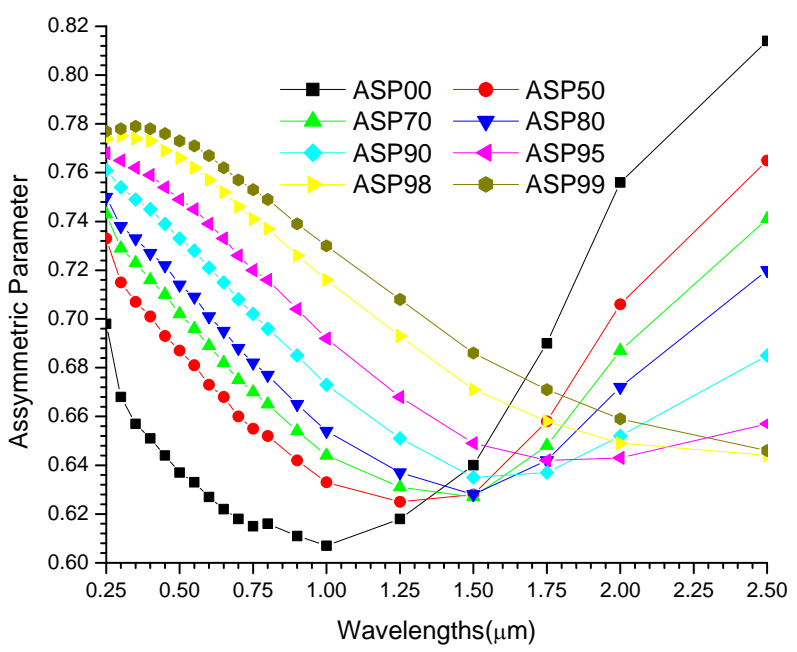

Figure 13. A plot of Asymmetric parameter against wavelength.

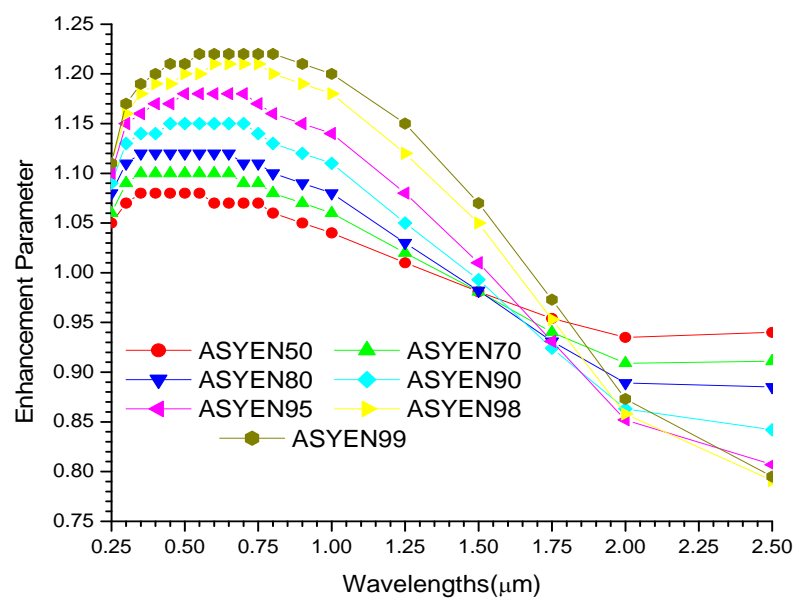

Figure 14. A plot of Asymmetric parameter enhancement parameters against wavelengths.

despite the higher fractions of more strongly absorbing particles, very low values of $g f_{\text {mix }}(\mathrm{RH})$ were observed, and this is in line with what Sheridan et al. [24] determined.

It shows that increase in RH increases forward scattering because particle growth enhances forward.

These hygroscopic growth behaviors also reveal an immense potential of light scattering enhancement in the forward scattering [65] for smaller particles while in larger particles it causes increase in the backward scattering at high humidities and the potential for being highly effective cloud condensation nuclei.

It also shows that the mixture is internally mixed for smaller particles because of the increase in forward scattering as a result of the hygroscopic growth [66].

Field measurements have noted a $\mathrm{k}$ value of 0.01 for fresh soot rich biomass [67]. The overall, modeled $\mathrm{k}$ ranges from 0.012 to 0.163 depending on the $\mathrm{RH}$ and the 
type of the mixing ratio used.

Finally, it can be observed that the absorption and scattering coefficients together with their enhancement parameters have exponential dependence with RH.

The modeling shows that hygroscopic growth at higher relative humidity increases the effective radii, scattering coefficients, scattering enhancement parameters, absorption coeffeicnts, absorption enhancement parameters, but decreases effective real refractive indices, effective imaginary refractive indices. However, the asymmetric and enhancement asymmetric parameters increase with the increase in $\mathrm{RH}$ but decreases with the increase in wavelength.

Jeong et al. [10] demonstrated an exponential dependence of the aerosol optical thickness on relative humidity.

Finally, the data fit our models very well and can be used to extrapolate the hygroscopic growth at any RH and enhancement parameters at any $\mathrm{RH}$ and wavelengths. The importance of determining $g f_{\text {mix }}(\mathrm{RH})$ as a function of $\mathrm{RH}$ and volume fractions, mass fractions and number fractions, and enhancement parameters as a function of $\mathrm{RH}$ and wavelengths can be potentially important because it can be used for efficiently representing aerosols-water interactions in global models.

\section{REFERENCES}

[1] D. A. Randall, R. A. Wood, S. Bony, R. Colman, T. Fichefet, J. Fyfe, V. Kattsov, A. Pitman, J. Shukla, J. Srinivasan, R. J. Stouf-fer, A. Sumi and K. E. Taylor, "Contribution of Working Group I to the Fourth Assessment Report of the Intergovernmental Panel on Climate Change-Climate Models and their Evaluation," Cambridge University Press, Cambridge, New York, 2007, pp. 589-662.

[2] D. S. Covert, R. J. Charlson and N. C. Ahlquist, "A Study of the Relationship of Chemical Composition and $\mathrm{Hu}-$ midity to Light Scattering by Aerosols," Journal of Applied Meteorology, Vol. 11, No. 6, 1972, pp. 968-976. http://dx.doi.org/10.1175/1520-0450(1972)011<0968:AS OTRO $>2.0 . \mathrm{CO} ; 2$

[3] L. McInnes, M. Bergin, J. Ogren and S. Schwartz, "Apportionment of Light Scattering and Hygroscopic Growth to Aerosol Composition," Geophysical Research Letters, Vol. 25, No. 4, 1998, pp. 513-516. http://dx.doi.org/10.1029/98GL00127

[4] R. A. Kotchenruther, P. V. Hobbs and D. A. Hegg, "Humidification Factors for Atmospheric Aerosols off the Mid-Atlantic Coast of the United States," Journal of Geophysical Research, Vol. 104, No. D2, 1999, pp. 22392251. http://dx.doi.org/10.1029/98JD01751

[5] W. C. Malm, D. E. Day, S. M. Kreidenweis, J. L. Collett and T. Lee, "Humidity-Dependent Optical Properties of Fine Particles during the Big Bend Regional Aerosol and Visibility Observational Study," Journal of Geophysical Research, Vol. 108, No. D9, 2003, p. 4279.
http://dx.doi.org/10.1029/2002JD002998

[6] I. N. Tang, "Chemical and Size Effects of Hygroscopic Aerosols on Light Scattering Coefficient," Journal of Geophysical Research, Vol. 101, No. D14, 1996, pp. 19245-19250. http://dx.doi.org/10.1029/96JD03003

[7] E. Swietlicki, J. Zhou, O. H. Berg, B. G. Martinsson, G. Frank, S.-I. Cederfelt, U. Dusek, A. Berner, W. Birmilli, A. Wiedensohler, B. Yuskiewicz and K. N. Bower, "A Closure Study of Sub-Micrometer Aerosol Particle Hygroscopic Behaviour," Atmospheric Research, Vol. 50 No. 3-4, 1999, pp. 205-240. http://dx.doi.org/10.1016/S0169-8095(98)00105-7

[8] S. A. Terpugowa, M. V. Panchenko, V. S. Kozlov, V. V. Polkin and E. P. Yausheva, "The Study of the Growth Factor of the Aerosol Scattering Coefficient in the NearGround Layer of the Atmosphere in West Siberia," European Aerosol Conference, Budapest, 2004

[9] J. Kuśmierczyk-Michulec, "Angstrom Coefficient as an Indicator of the Atmospheric Aerosol Type for a WellMixed Atmospheric Boundary Layer: Part 1: Modeldevelopment," Oceanologia, Vol. 51 No. 1, 2009, pp. 5-38. http://dx.doi.org/10.5697/oc.51-1.005

[10] M. J Jeong, Z. Li, E. Andrews and S. C. Tsay, "Effect of Aerosol Humidification on the Column Aerosol Optical Thickness over the Atmospheric Radiation Measurement Southern Great Plains Site," Journal of Geophysical Research, Vol. 112, No. D10, 2007, p. 202. http://dx.doi.org/10.1029/2006JD007176

[11] A. S. Rapti, "Spectral Optical Atmospheric Thickness Dependence on the Specific Humidity in the Presence of Continental and Marine Air Masses," Atmospheric Research, Vol. 78, No. 1-2, 2005, pp. 13-32. http://dx.doi.org/10.1016/j.atmosres.2005.02.004

[12] Y. Miyazaki, Y. Kondo, N. Takegawa, Y. Komazaki, M. Fukuda, K. Kawamura, M. Mochida, K. Okuzawa and R. J. Weber, "Time-Resolved Measurements of Water-Soluble Organic Carbon in Tokyo," Journal of Geophysical Research, Vol. 111, No. D23, 2006, p. 206. http://dx.doi.org/10.1029/2006JD007125

[13] A. P. Sullivan, R. E. Peltier, C. A. Brock, J. A. de Gouw, J. S. Holloway, C. Warneke, A. G. Wollny and R. J. Weber, "Airborne Measurements of Carbonaceous Aerosol Soluble in Water over Northeastern United States: Method Development and an Investigation into Water-Soluble Organic Carbon Sources," Journal of Geophysical Research, Vol. 111, No. D23, 2006, p. S46. http://dx.doi.org/10.1029/2006JD007072

[14] Y. Kondo, Y. Miyazaki, N. Takegawa, T. Miyakawa, R. J. Weber, J. L. Jimenez, Q. Zhang and D. R. Worsnop, "Oxygenated and Water-Soluble Organic Aerosols in Tokyo," Journal of Geophysical Research, Vol. 122, No. D01, 2007, p. 203. http://dx.doi.org/10.1029/2006JD007056

[15] R. J. Weber, A. P. Sullivan, R. E. Peltier, A. Russell, B. Yan, M. Zheng, J. de Gouw, C. Warneke, C. Brock, J. S. Holloway, E. L. Atlas and E. Edgerton, "A Study of Secondary Organic Aerosol Formation in the Anthropogenic Influenced Southeastern United States," Journal of Geophysical Research, Vol. 112, No. D13, 2007, p. 302. 
http://dx.doi.org/10.1029/2007JD008408

[16] B. Ervens and R. Volkamer, "Glyoxal Processing by Aerosol Multiphase Chemistry: Towards a Kinetic Modeling Framework of Secondary Organic Aerosol Formation in Aqueous Particles," Atmospheric Chemistry and Physics, Vol. 10, 2010, pp. 8219-8244.

http://dx.doi.org/10.5194/acp-10-8219-2010

[17] A. Sorooshian, S. M. Murphy, S. Hersey, R. Bahreini, H. Jonsson, R. C. Flagan and J. H. Seinfeld, "Constraining the Contribution of Organic Acids and AMS m/z44 to the Organic Aerosol Budget: On the Importance of Meteorology, Aerosol Hygroscopicity and Region," Geophysical Research Letters, Vol. 37, No. 21, 2010. http://dx.doi.org/10.1029/2010GL044951

[18] H. Timonen, M. Aurela, S. Carbone, K. Saarnio, S. Saarikoski, T. Makela, M. Kulmala, V. M. Kerminen, D. R. Worsnop and R. Hillamo, "High Time-Resolution Chemical Characterization of the Water-Soluble Fraction of Ambient Aerosols with PILS-TOC-IC and AMS," Atmospheric Measurement Techniques, Vol. 3, 2010, pp. 1063-1074. http://dx.doi.org/10.5194/amt-3-1063-2010

[19] K. S. Docherty, E. A. Stone, I. M. Ulbrich, P. F. DeCarlo, D. C. Snyder, J. J. Schauer, R. E. Peltier, R. J. Weber, S. M. Murphy, J. H. Seinfeld, D. J. Eatough, B. D. Grover and J. L. Jimenez, "Apportionment of Primary and Secondary Organic Aerosols in Southern California during the 2005 Study of Organic Aerosols in Riverside (SOAR)," Environmental Science \& Technology, Vol. 42, No. 20, 2008, pp. 7655-7662.

[20] P. McMurry and M. Stolzenburg, "On the Sensitivity of Particle Size to Relative Humidity for Los Angeles Aerosols," Atmospheric Environment, Vol. 23, No. 2, 1989, pp. 497-507.

http://dx.doi.org/10.1016/0004-6981(89)90593-3

[21] D. Cocker, N. Whitlock, R. Flagan and J. H. Seinfeld, "Hygroscopic Properties of Pasadena, California Aerosol," Aerosol Science and Technology, Vol. 35, No. 2, 2001, pp. 637-647. http://dx.doi.org/10.1080/02786820120653

[22] E. Swietlicki, et al., "Hygroscopic Properties of Submicrometer Atmospheric Aerosol Particles Measured with $\mathrm{H}$ TDMA Instruments in Various Environments-A Review," Tellus B, Vol. 60, No. 3, 2008, pp. 432-469. http://dx.doi.org/10.3402/tellusb.v60i3.16936

[23] H. Kohler, "The Nucleus and Growth of Hygroscopic Droplets," Transactions of the Faraday Society, Vol. 32, 1936, pp. 1152-1161. http://dx.doi.org/10.1039/tf9363201152

[24] P. J. Sheridan, D. J. Delene and J. A. Ogren, "Four Years of Continuous Surface Aerosol Measurements from the Department of Energy's Atmospheric Radiation Measurement Program Southern Great Plains Cloud and Radiation Testbedsite," Journal of Geophysical Research, Vol. 106, No. 20, 2001, pp. 735-747. http://dx.doi.org/10.1029/2001JD000785

[25] M. Hess, P. Koepke and I. Schult, "Optical Properties of Aerosols and Clouds: The Software Package OPAC," Bulletin of the American Meteorological Society, Vol. 79, No. 5, 1998, pp. 831-844.
[26] C. A. Randles, L. M. Russell and V. Ramaswamy, "Hygroscopic and Optical Properties of Organic Sea Salt Aerosol and Consequences for Climate Forcing," Geophysical Research Letters, Vol. 31, No. 16, 2004, Article ID: L16108. http://dx.doi.org/10.1029/2004GL020628

[27] P. F. Liu, C. S. Zhao, T. Gobel, E. Hallbauer, A. Nowak, L. Ran, W. Y. Xu, Z. Z. Deng, N. Ma, K. Mildenberger, S. Henning, F. Stratmann and A. Wiedensohler, "Hygroscopic Proper Ties of Aerosol Particles at High Relative Humidity and Their Diurnal Variations in the North China Plain," Atmospheric Chemistry and Physics, Vol. 11, 2011, pp. 2991-3040. http://dx.doi.org/10.5194/acpd-11-2991-2011

[28] G. Buzorius, A. Zelenyuk, F. Brechtel and D. Imre, "Simultaneous Determination of Individual Ambient Particle Size, Hygroscopicity and Composition," Geophysical Research Letters, Vol. 29, 1974, 2002. http://dx.doi.org/10.1029/2001GL014221

[29] S. Sjogren, M. Gysel, E. Weingartner, U. Baltensperger, M. J. Cubison, H. Coe, A. A. Zardini, C. Marcolli, U. K. Krieger and T. Peter, "Hygroscopic Growth and Water Uptake Kinetics of Two-Phase Aerosol Particles Consisting of Ammonium Sulfate, Adipic and Humic Acid Mixtures," Journal of Aerosol Science, Vol. 38, No. 2, 2007 , 157-171. http://dx.doi.org/10.1016/j.jaerosci.2006.11.005

[30] R. H. Stokes and R. A. Robinson, "Interactions in Aqueous Nonelec-trolyte Solutions. I. Solute-Solvent Equilibria," The Journal of Physical Chemistry, Vol. 70, No. 7, 1966, pp. 2126-2130. http://dx.doi.org/10.1021/j100879a010

[31] N. K. Meyer, J. Duplissy, M. Gysel, A. Metzger, J. Dommen, E. Weingartner, M. R. Alfarra, A. S. H. Prevot, C. Fletcher, N. Good, G. McFiggans, A. M. Jonsson, M. Hallquist, U. Baltensperger and Z. D. Ristovski, "Analysis of the Hy-groscopic and Volatile Properties of Ammonium Sulphate Seeded and Unseeded SOA Particles," Atmospheric Chemistry and Physics, Vol. 9, 2009, pp. 721-732. http://dx.doi.org/10.5194/acp-9-721-2009

[32] M. Stock, Y. F. Cheng, W. Birmili, A. Massling, B. Wehner, T. Muller, S. Leinert, N. Kalivitis, N. Mihalopoulos and A. Wiedensohler, "Hygroscopic Properties of Atmospheric Aerosol Particles over the Eastern Mediterranean: Implications for Regional Direct Radiative Forcing under Clean and Polluted Conditions," Atmospheric Chemistry and Physics, Vol. 11, 2011, pp. 4251-4271. www.atmos-chem-phys.net/11/4251/2011/ http://dx.doi.org/10.5194/acp-11-4251-2011

[33] J. Duplissy, P. F. DeCarlo, J. Dommen, M. R. Alfarra, A. Metzger, I. Barmpadimos, A. S. H. Prevot, E. Weingartner, T. Tritscher, M. Gysel, A. C. Aiken, J. L. Jimenez, M. R. Canagaratna, D. R. Worsnop, D. R. Collins, J. Tomlinson and U. Baltensperger, "Relating Hygroscopicity and Composition of Organic Aerosol Particulate Matter," Atmospheric Chemistry and Physics, Vol. 11, 2011, pp. 1155-1165.

www.atmos-chem-phys.net/11/1155/2011/ http://dx.doi.org/10.5194/acp-11-1155-2011

[34] J. Meier, B. Wehner, A. Massling, W. Birmili, A. Nowak, T. Gnauk, E. Bruggemann, H. Herrmann, H. Min and A. Wiedensohler, "Hygroscopic Growth of Urban Aerosol 
Particles in Beijing (China) during Wintertime: A Comparison of Three Experimental Methods," Atmospheric Chemistry and Physics, Vol. 9, 2009, pp. 6865-6880. www.atmos-chem-phys.net/9/6865/2009/ http://dx.doi.org/10.5194/acp-9-6865-2009

[35] M. D. Petters and S. M. Kreidenweis, "A Single Parameter Representation of Hygroscopic Growth and Cloud Condensation Nucleus Activity," Atmospheric Chemistry and Physics, Vol. 7, No. 8, 2007, pp. 1961-1971. http://dx.doi.org/10.5194/acp-7-1961-2007

[36] J. H. Seinfeld and S. N. Pandis, "Atmospheric Chemistry and Physics," Wiley-Interscience Publication, Hoboken, 1998.

[37] J. Seinfeld and S. Pandis, "Atmospheric Chemistry and Physics," 2nd Edition, Wiley-Interscience, New York, 2006.

[38] E. Swietlicki, J. Zhou, D. S. Covert, K. Hameri, B. Busch, M. Vakeva, U. Dusek, O. H. Berg, A. Wiedensohler, P. Aalto, J. Makela, B. G. Martinsson, G. Papaspiropoulos, B. Mentes, G. Frank and F. Stratmann, "Hygroscopic Properties of Aerosol Particles in the Northeastern Atlantic during ACE-2," Tellus, Vol. 52, No. 2, 2000, pp. 201227.

[39] W. Birmili, A. Nowak, K. Schwirn, K. Lehmann, et al., "A New Method to Accurately Relate Dry and Humidified Number Size Distributions of Atmospheric Aerosols," Journal of Aerosol Science, Vol. 1, No. 1, 2004, pp. $15-16$.

[40] F. Kasten, "Visibility Forecast in the Phase of Pre-Condensation," Tellus, Vol. 21, No. 5, 1969, pp. 631-635.

[41] M. Gysel, G. B. McFiggans and H. Coe, "Inversion of Tandem Differential Mobility Analyser (TDMA) Measurements," Journal of Aerosol Science, Vol. 40, No. 2, 2009, pp. 134-151. http://dx.doi.org/10.1016/j.jaerosci.2008.07.013

[42] J.-P. Putaud, "Interactive Comment on 'Aerosol Hygroscopicity at Ispra EMEP-GAW Station' by M. Adam et al.," Atmospheric Chemistry and Physics Discussions, Vol. 12, No. 1, 2012, pp. C200-C202.

[43] S. I. Christensen and M. D. Petters, "The Role of Temperature in Cloud Droplet Activation," The Journal of Physical Chemistry A, Vol. 116, No. 39, 2012, pp. 97069717. http://dx.doi.org/10.1021/jp3064454

[44] S. J. Doherty, et al., "A Comparison and Summary of Aerosol Optical Properties as Observed in Situ from Aircraft, Ship, and Land during ACE-Asia," Journal of Geophysical Research: Atmospheres, Vol. 110, No. D4, 2005, Article ID: D04201. http://dx.doi.org/10.1029/2004JD004964

[45] P. K. Quinn, et al., "Impact of Particulate Organic Matter on the Relative Humidity Dependence of Light Scattering: A Simplified Parameterization," Geophysical Research Letters, Vol. 32, No. 22, 2005, Article ID: L22809. http://dx.doi.org/10.1029/2005GL024322

[46] S. Gasso, et al., "Influence of Humidity on the Aerosol Scattering Coefficient and Its Effect on the Upwelling Radiance during ACE-2," Tellus B, Vol. 52, No. 2, 2000, pp. 546-567.
[47] A. Clarke, et al., "Biomass Burning and Pollution Aerosol over North America: Organic Components and Their Influence on Spectral Optical Properties and Humidification Response," Journal of Geophysical Research: Atmospheres, Vol. 112, No. D12, 2007, Article ID: D12S18. http://dx.doi.org/10.1029/2006JD007777

[48] G. Hanel, "The Properties of Atmospheric Aerosol Particles as Functions of Relative Humidity at Thermodynamic Equilibrium with Surrounding Moist Air," In: H. E. Landsberg and J. Van Mieghem, Eds., Advances in Geophysics, Academic Press, New York, 1976, pp. 73-188.

[49] M. K. Latha and K. V. S. Badarinath, "Factors Influencing Aerosol Characteristics over Urban Environment," Environmental Monitoring and Assessment, Vol. 104, No. $1-3,2005$, pp. 269-280. http://dx.doi.org/10.1007/s10661-005-1615-7

[50] A. Angstrom, "Techniques of Determining the Turbidity of the Atmosphere," Tellus, Vol. 13, No. 2, 1961, pp. 214223. http://dx.doi.org/10.1111/j.2153-3490.1961.tb00078.x

[51] M. D. King and D. M. Byrne, "A Method for Inferring Total Ozone Content from Spectral Variation of Total Optical Depth Obtained with a Solar Radiometer," Journal of the Atmospheric Sciences, Vol. 33, No. 11, 1976, pp. 2242-2251.

http://dx.doi.org/10.1175/1520-0469(1976)033<2242:AM FITO $>2.0 . \mathrm{CO} ; 2$

[52] T. F. Eck, B. N. Holben, J. S. Reid, O. Dubovic, A. Smirnov, N. T. O’Neil, I. Slutsker and S. Kinne, "Wavelength Dependence of the Optical Depth of Biomass Burning, Urban, and Desert Dust Aerosols," Journal of Geophysical Research: Atmospheres, Vol. 104, No. D24, 1999, pp. 31333-31349.

[53] T. F. Eck, B. N. Holben, O. Dubovic, A. I. Smirnov, J. Slutsker, M. Lobert and V. Ramanathan, "Column-Integrated Aerosol Optical Properties over the Maldives during the Northeast Mon-Soon for 1998-2000," Journal of Geophysical Research: Atmospheres, Vol. 106, 2001, pp. 28555-28566.

[54] T. F. Eck, B. N. Holben, D. E. Ward, O. Dubovic, J. S. Reid, A. Smirnov, M. M. Mukelabai, N. C. Hsu, N. T. O' Neil and I. Slutsker, "Characterization of the Optical Properties of Biomass Burning Aerosols in Zambia during the 1997 ZIBBEE Field Campaign," Journal of Geophysical Research: Atmospheres, Vol. 106, No. D4, 2001, pp. 3425-3448. http://dx.doi.org/10.1029/2000JD900555

[55] Y. J. Kaufman, "Aerosol Optical Thickness and Atmospheric Path Radiance," Journal of Geophysical Research: Atmospheres, Vol. 98, No. D2, 1993, pp. 2677-2992. http://dx.doi.org/10.1029/92JD02427

[56] N. T. O’Neill, O. Dubovic and T. F. Eck, "Modified Ångström Exponent for the Characterization of Submicrometer Aerosols," Applied Optics, Vol. 40, No. 15, 2001, pp. 2368-2375. http://dx.doi.org/10.1364/AO.40.002368

[57] N. T. O’Neill, T. F. Eck, A. Smirnov, B. N. Holben and S. Thulasiraman, "Spectral Discrimination of Coarse and Fine Mode Optical Depth," Journal of Geophysical Research: Atmospheres, Vol. 108, No. D17, 2003. 
[58] R. Pedros, J. A. Martinez-Lozano, M. P. Utrillas, J. L. Gomez-Amo and F. Tena, "Column-Integrated Aerosol, Optical Properties from Ground-Based Spectroradiometer Measurements at Barrax (Spain) during the Digital Airborne Imaging Spectrometer Experiment (DAISEX) Campaigns," Journal of Geophysical Research: Atmospheres, Vol. 108, No. D18, 2003, pp. 1-12. http://dx.doi.org/10.1029/2002JD003331

[59] D. G. Kaskaoutis and H. D. Kambezidis, "Investigation on the Wavelength Dependence of the Aerosol Optical Depth in the Athens Area," Quarterly Journal of the Royal Meteorological Society, Vol. 132, No. 620, 2006, pp. 2217-2234. http://dx.doi.org/10.1256/qi.05.183

[60] B. Schmid, D. A. Hegg, J. Wang, D. Bates, J. Redemann, P. B. Russell, J. M. Livingston, H. H. Jonsson, E. J. Welton, J. H. Seinfeld, R. C. Flagan, D. S. Covert, O. Dubovik and A. Jefferson, "Column Closure Studies of Lower Tropospheric Aerosol and Water Vapor during ACE-Asia Using Airborne Sun Photometer and Airborne in Situ and Ship-Based Lidar Measurements," Journal of Geophysical Research: Atmospheres, Vol. 108, No. D23, 2003, pp. 1-19. http://dx.doi.org/10.1029/2002JD003361

[61] J. A. Martinez-Lozano, M. P. Utrillas, F. Tena, R. Pedros, J. Canada, J. V. Bosca and J. Lorente, "Aerosol Optical Characteristics from Summer Campaign in an Urban Coastal Mediterranean Area," IEEE Transactions on Geoscience and Remote Sensing, Vol. 39, No. 7, 2001, pp. 15731585. http://dx.doi.org/10.1109/36.934089

[62] D. E. Aspens, "Local-Field Effect and Effective Medium Theory: A Microscopic Perspective," American Journal of Physics, Vol. 50, No. 8, 1982, pp. 704-709. http://dx.doi.org/10.1119/1.12734

[63] H. A. Lorentz, "Ueber Die Beziehungzwischen der Fortpflanzungsgeschwindigkeit des Lichtes und der Körperdichte," Annalen der Physik, Vol. 245, No. 4, 1880, pp. 641-665. http://dx.doi.org/10.1002/andp.18802450406

[64] L. Lorenz, "Ueber Die Refractionconstante," Annalen der Physik, Vol. 11, No. 1, 1880, pp. 70-103.

[65] K. N. Liou, "An Introduction to Atmospheric Radiation,"
Elsevier, New York, 2002.

[66] J. Wang and S. T. Martin, "Satellite Characterization of Urban Aerosols: Importance of Including Hygroscopicity and Mixing State in the Retrieval Algorithms," Journal of Geophysical Research: Atmospheres, Vol. 112, No. D17203, 2007, pp. 1-18.

http://dx.doi.org/10.1029/2006JD008078

[67] M. O. Andreae and D. Rosenfeld, "Aerosol-Cloud-Precipitation Interactions. Part 1. The Nature and Sources of Cloud-Active Aerosols," Earth-Science Reviews, Vol. 89, No. 1-2, 2008, pp. 13-41. http://dx.doi.org/10.1016/j.earscirev.2008.03.001

[68] T. F. Eck, B. N. Holben, D. E. Ward, M. M. Mukelabai, O. Dubovik, A. Smirnov, J. S. Schafer, N. C. Hsu, S. J. Piketh, A. Queface, J. Le Roux, R. J. Swap and I. Slutsker, "Variability of Biomass Burning Aerosol Optical Characteristics in Southern Africa during the SAFARI 2000 Dry Season Campaign and a Comparison of Single Scattering Albedo Estimates from Radiometric Measurements," Journal of Geophysical Research: Atmosphere, Vol. 108, No. D13, 2003, pp.

[69] G. L. Schuster, O. Dubovik and B. N. Holben, "Angstrom Exponent and Bimodal Aerosol Size Distributions," Journal of Geophysical Research: Atmosphere, Vol. 111, No. D17, 2006, Article ID: D07207. http://dx.doi.org/10.1029/2005JD006328

[70] D. G. Kaskaoutis, H. D. Kambezidis, N. Hatzianastassiou, P. G. Kosmopoulos and K. V. S. Badarinath, "Aerosol Climatology: Dependence of the Angstrom Exponent on Wavelength over Four AERONET Sites," Atmospheric Chemistry and Physical Discussion, Vol. 7, No. 3, 2007, pp. 7347-7397.

http://dx.doi.org/10.5194/acpd-7-7347-2007

[71] D. G. Kaskaoutis, H. D. Kambezidis, N. Hatzianastassiou, P. G. Kosmopoulos and K. V. S. Badarinath, "Aerosol Climatology: On the Discrimination of Aerosol Types over four AERONET Sites," Atmospheric Chemistry and Physical Discussion, Vol. 7, No. 3, 2007, pp. 6357-6411. http://dx.doi.org/10.5194/acpd-7-6357-2007 